\title{
MAGISTÉRIO E CONFLITOS URBANOS: \\ NARRATIVAS E POSICIONAMENTOS DISCURSIVOS DE PROFESSORES EM \\ CONTEXTOS MARCADOS PELA VIOLÊNCIA
}

Viviane dos Santos Cavalcanti*

\section{Resumo}

A presente pesquisa observa uma escola estadual localizada em um bairro no estado do Rio de Janeiro que vem sofrendo mudanças relacionadas aos conflitos urbanos nos últimos anos. Estudando as construções narrativas e os posicionamentos (BAMBERG, 1997; 2002), a pesquisa buscou compreender como os professores constroem suas identidades, lidam com os desafios da violência e se posicionam em relação a Discursos sobre educação e violência.

\section{Palavras-chave}

Escola Pública. Identidade de professores. Narrativas. Histórias de vida. Posicionamentos.

\section{1) Introdução}

O presente artigo tem por objetivo apresentar alguns resultados da minha dissertação. Por fazer menção às experiências pessoais dos participantes, as narrativas são analisadas como histórias de vida que constroem o self, isto é, quem somos e como nos transformamos no que somos (LINDE, 1993). Ademais, as narrativas apresentam-se como centrais no entendimento sobre a vida social, posto que elas nos possibilitam observar como nos posicionamos em relação às situações e aos outros (MOITA LOPES, 2001).

Nesta pesquisa, realizada através de seis entrevistas gravadas em áudio com seis professores e colegas de trabalho em uma escola da rede pública do Rio de Janeiro, tenho como objetivo geral produzir conhecimento sobre o que é ser professor diante das adversidades ocasionadas pelos desafios dos conflitos urbanos.

Refletir sobre a membridade dos professores na comunidade onde trabalham e seus desafios causados pela violência são questões que estão entrelaçadas ao objetivo do meu questionamento. Portanto, a análise interpretativa dos dados foi orientada para

\footnotetext{
* É professora de língua inglesa e mestre em Estudos da Linguagem pela PUC-Rio. É graduada em Letras com licenciatura plena em Português/Inglês pela Universidade do Estado do Rio de Janeiro e bacharelado em Português/Italiano pela Universidade Federal do Rio de Janeiro. Email:vivicavalcantiletras@yahoo.com.br
} 
responder a três perguntas de pesquisa, que constituem os objetivos específicos da dissertação: (i) Como os professores de escola pública em uma área periférica se posicionam em relação as suas histórias de vida e trajetórias profissionais?; (ii) Quais são seus posicionamentos que emergem nas narrativas quanto aos desafios causados pela violência?; (iii) Como os professores se posicionam em relação a Discursos circulantes sobre educação e violência?

\section{2) Ingressar no meio acadêmico, tornar-se professor apesar das adversidades}

Conseguir uma vaga e permanecer no ensino superior, principalmente em uma universidade pública, acaba se tornando uma jornada com desafios para os que vêm de uma família de baixa renda. Atualmente, pode-se dizer que, comparado às décadas anteriores, o espaço universitário no Brasil, após algumas medidas como o PROUNI (Programa Universidade Para Todos) e a política de cotas (conforme lei 12.711) durante o governo Lula, está mais favorável às camadas socioeconomicamente desfavorecidas. Houve um processo de democratização da educação superior no país, em que novos meios de diferenciação acabaram reorganizando as vagas para a inclusão de grupos economicamente excluídos no interior do sistema de ensino universitário brasileiro. No Brasil, as políticas de ação afirmativa assumiram grande destaque e ainda merecem uma referência especial, conforme afirma Santos (2004):

em reposta à crescente pressão de movimentos sociais pela democratização do acesso ao ensino superior, especialmente do movimento negro, O Governo Lula lançou no primeiro semestre de 2004 o programa "Universidade para Todos" (PROUNI) que preconiza uma ação afirmativa baseada em critérios raciais e socioeconômicos. Dois projetos de lei elaborados pelo Ministério da Educação já encaminhados ao Congresso Nacional definem o escopo e os instrumentos dessa nova política de inclusão social no ensino superior. (SANTOS, 2004, p. 70-71).

Segundo Santos (2004), o primeiro projeto previa bolsa de estudo integral para alunos de baixa renda concedida pelas próprias instituições privadas de ensino superior em troca da manutenção das isenções fiscais e previdenciárias já concedidas pelo Estado. Essas instituições passaram a destinar pelo menos $10 \%$ das suas vagas para estudantes de baixa renda e professores da rede pública de educação básica. A segunda proposta legislativa determinou que as instituições públicas federais de educação superior 
deveriam destinar pelo menos 50\% das suas vagas para estudantes de escolas públicas, cabendo às respectivas instituições de educação superior fixar o percentual de vagas a serem preenchidas por estudantes negros e indígenas. Indubitavelmente, essas propostas representam um esforço meritório no sentido de combater o tradicional elitismo social da universidade pública.

Portanto, a vida universitária de sujeitos vindos de camadas populares é algo relativamente bem recente em termos históricos em nosso país e, mesmo assim, ainda é um desafio. Ser aprovado no ENEM ou no vestibular em uma universidade pode dar a muitos estudantes a sensação de missão cumprida, no entanto para a grande maioria dos alunos de baixa renda (SANTOS, 2004), conquistar uma vaga na universidade é apenas o primeiro passo, pois o maior problema desses estudantes está na dificuldade de se manter em uma universidade em função dos gastos que surgem logo ao iniciar a carreira universitária. Por isso, é importante a efetivação de políticas públicas voltadas para o ensino superior que garantam o acesso e a permanência do aluno, a equidade de oportunidades e a efetivação da democratização do espaço acadêmico.

Para transpor a barreira universitária e obter ascensão social diante da escassez de recursos da família, estudantes de camadas populares buscam se formar e trabalhar na área de ensino, pois há mais possibilidades de mobilidade socioeconômica, seja trabalhando em instituições privadas de ensino ou, ao término da graduação, em instituições públicas de ensino (PORTES, 2001). Conseguiremos visualizar melhor essa questão através dos excertos desta pesquisa. Sobre a escolha da carreira, segundo Linde (1993), a profissão exercida pelos sujeitos constitui uma grande compreensão sobre as suas vidas. A autora também ressalta que há profissões nas quais ninguém precisa explicar o motivo para ter escolhido segui-las, como ser médico, por exemplo. Porém, há outras que necessitam constantemente de justificativa para a sua escolha porque são vistas culturalmente sob um olhar negativo, como ser professor (LINDE, 1993).

$\mathrm{O}$ aumento das exigências em relação à atividade docente na atualidade é um aspecto que merece destaque. O trabalho do professor está cada vez mais complexo e tem exigido uma responsabilidade cada vez maior. As demandas contemporâneas estabelecem uma nova dinâmica no cotidiano das instituições de ensino que se reflete diretamente sobre o trabalho dos professores. Como explica Fanfani (2007), a sociedade espera mais do que a escola pode produzir, ou seja, existe uma distância entre a imagem ideal da função docente e a realidade relacional e temporal da sua prática. No cotidiano da escola, o professor, para desenvolver sua atividade de ensino, precisa lidar com a violência, com 
a necessidade de trabalhar com um número maior de alunos e desenvolver sua tarefa educativa na e para a diversidade.

Veremos ao longo deste estudo que os professores participantes e eu, no papel híbrido de pesquisadora e participante, viemos de camadas populares e enfrentamos desafios socioeconômicos para conseguir o ingresso acadêmico e permanência na universidade pública. Portanto, a universidade pública tem um papel imensurável na transformação socioeconômica de muitas pessoas, embora tenhamos políticas públicas que parecem contribuir para o sucateamento dessas universidades como a falta de verba e incentivos públicos. Além disso, segundo Ferreira (2003), muitos professores conseguiram superar a situação de vida dos seus familiares e isso significa que o magistério é também uma das poucas carreiras a permitir movimentos de ascensão social.

\section{3) $O$ campo de pesquisa}

Este estudo foi realizado com seis professores que trabalham e moram no município de São Gonçalo, que se divide em cinco distritos: São Gonçalo, Monjolos, Neves, Sete Pontes e Ipiiba. O bairro Jardim Catarina, onde fica a escola em que os professores participantes e eu trabalhamos, está localizado no distrito de Monjolos, periferia do município. São Gonçalo tem sua história de formação caracterizada pelo processo de modernização da Região Metropolitana do Rio de Janeiro, resultante de um demorado processo de urbanização, sendo, além disso, um reservatório de mão-de-obra barata ainda nos dias atuais, notadamente formada por emigrantes de várias localidades, principalmente nordestinos (PINHO, 2006).

O desenvolvimento econômico e urbano da região permitiu a aglomeração populacional na área, que avançou com a criação da ponte Presidente Costa e Silva, popularmente chamada de Ponte Rio-Niterói, em 1974. Com o processo de industrialização, a migração das áreas rurais e o consequente declínio das lavouras, o município de São Gonçalo apresentou aumento demográfico (DOMINGUEZ, 2012). De acordo com Mendes (2012, p.18), "além de possuir grandes áreas propícias à moradia, o município localizava-se relativamente próximo da capital federal. As áreas de fazendas e sítios de São Gonçalo acabaram se tornando focos de loteamentos”. Sendo assim, alguns loteamentos surgiram, dentre eles: Laranjal, Santa Luzia e Jardim Catarina. Porém, esse último será o foco dessa investigação por ser o local onde se localiza a escola ora pesquisada. 
Com o propósito de atrair compradores para o loteamento, foram feitas propagandas que promovessem o mercado imobiliário e a venda das terras no bairro Jardim Catarina, porém as pessoas não encontraram o que esperavam. Conforme salienta Mendes (2012), a partir desse momento, São Gonçalo começou a viver um processo de periferização, ou seja, o surgimento de áreas transformadas em bairros periféricos, notadamente ocupados pela população mais pobre. Tavares (2003) acrescenta que a periferização da cidade de São Gonçalo e dos loteamentos, depois transformados em bairros, apresenta aspectos relacionados à ausência de políticas públicas locais, o que redundou na construção de novos espaços/tempos, lógicas diferenciadas de ocupação espacial e de sobrevivência urbana.

Nos dias atuais, algumas ruas do bairro foram asfaltadas, porém a modernização presenteada pelo asfalto somada à entrada das UPPs (Unidades de Polícia Pacificadora ${ }^{1}$ ) nas periferias da cidade do Rio de Janeiro trouxe ao bairro novas preocupações como a chegada de facções não-locais e, consequentemente, a violência ocasionada pelo tráfico de drogas e a facilidade de escoamento do produto.

De acordo com o ponto de vista do direito à cidade, das políticas urbanas e da urbanidade, quando amplia-se a pobreza, o desemprego e a precariedade urbana também há o aumento da violência urbana. Morre-se e mata-se muito na cidade São Gonçalo, principalmente nos bairros e loteamentos irregulares. Não há como não relacionar essas questões aos processos de educabilidade dos jovens, já que são justamente eles quem mais sofrem as repercussões da escalada da violência urbana em suas ruas e bairros, pois se tornam alvos fáceis das "balas perdidas", tanto dos traficantes, quanto da própria polícia, pouco preparada para intervenção nessas áreas de conflitos (TAVARES, 2010).

\section{4) Aspectos Metodológicos}

Pelo contexto, esta pesquisa não poderia estar inserida em outro paradigma a não ser o qualitativo interpretativista que considera "a natureza socialmente construída da realidade, a íntima relação entre o pesquisador e o que é estudado, e as limitações situacionais que influenciam a investigação" (DENZIN \& LINCOLN, 2006, p. 23). Além

\footnotetext{
${ }^{1}$ As UPPs fazem parte de uma política de segurança pública adotada no estado do Rio de Janeiro. Elas foram implementadas nas comunidades e favelas pelo Governo do Rio de Janeiro, a partir do ano de 2008, com o discurso de "guerra contra as drogas" e reforçando "um modelo de Estado Penal". A definição está calcada na dissertação de Marielle Franco, que foi publicada em 2014, cujo título é UPP - A redução da favela em três letras: uma análise da política pública de segurança do Estado do Rio de Janeiro.
} 
disso, a presente pesquisa se configura em interpretativista, pois se caracteriza pela busca, como princípio do conhecimento, de uma compreensão das complexas relações constituintes da realidade social. Ela parte da ideia de realidade como construção e “consiste em um conjunto de práticas materiais e interpretativas que dão visibilidade ao mundo" (DENZIN \& LINCOLN, 2006, p. 17).

Nesta pesquisa, a Linguística Aplicada (LA), a Sociolinguística Interacional (SI) e a Análise de Narrativa se inserem como arcabouço teórico-metodológico na medida em que tece uma análise interpretativa de histórias de vida (LINDE, 1993) e relatos de professores gerados em situação de entrevista, a fim de compreender o que é ser professor de escola pública em uma periferia e como os mesmos (re)constroem suas identidades, para si e para outros, com relação ao seu pertencimento à comunidade e aos desafios causados pela violência local.

Uma das principais vantagens das narrativas pessoais é que elas nos dão acesso aos mundos privados e fornecem dados ricos. Uma vantagem importante é o potencial do viés autoetnográfico ao contribuir na vida de outros, fazendo-os refletir e empatizar com as narrativas apresentadas (MÉNDEZ, 2013). Através da leitura de um relato cultural ou social de uma experiência, alguns podem tomar conhecimento de realidades que não foram pensadas antes, o que torna a autoetnografia uma valiosa forma de investigação. Ademais, concordo com Méndez (2013, p. 283) que considera que o principal critério a levar em conta é que "a autoetnografia em si já é uma prática ética" e os métodos qualitativos podem nos ajudar a entender melhor um fenômeno em uma determinada comunidade ou ambiente, uma vez que os resultados da pesquisa são inevitavelmente influenciados pelo background sociocultural dos participantes.

As entrevistas individuais aqui mencionadas e realizadas com cinco professoras e um professor são compreendidas como atividades de fala, ou seja, discursos coconstruídos entre entrevistados e entrevistadora (MISHLER, 1986), que agem no evento discursivo negociando e compartilhando significados. Por essa razão, aqui, "análises e interpretação de entrevistas são baseadas em uma teoria de discurso e significado" (MISHLER, 1986, p.66). De uma maneira prática, as entrevistas de pesquisa passam a acontecer de forma espontânea por meio de perguntas abertas ou semi-estruturadas (MINAYO, 1993), como neste estudo e, é possível penetrar pouco a pouco o mundo do entrevistado e perceber as suas reações, os seus intervalos silenciosos, seus movimentos mais simples. Desse modo, as perguntas mais abertas não conseguem funcionar como um roteiro pronto, mas como um convite amigável para um bom diálogo. 
A transcrição dos excertos das entrevistas foi baseada numa adaptação do modelo de Sacks, Schegloff e Jefferson (1974). A primeira entrevista foi realizada com a professora Michele em dezembro de 2017 e a última com a professora Jéssica em novembro de 2018. Além disso, todos os participantes receberam nomes fictícios na pesquisa. Ressalto que, para este artigo, foram selecionados excertos dos dados de pesquisa de apenas uma entrevista realizada com uma participante: Michele. Vejamos os dados sobre a professora-participante:

Michele: a professora é moradora do bairro Jardim Catarina desde a infância. Um de seus familiares trabalhava na escola onde ocorre a pesquisa e a levava lá algumas vezes quando ainda era criança. Posteriormente, decidiu cursar o Ensino Médio Normal e se formou em Letras (português-literaturas) pela UERJ-FFP lecionando português na escola para os ensinos fundamental e médio normal. Iniciou na Rede Estadual de Ensino após passar no concurso em 2006 e passou a trabalhar na escola onde ocorre a pesquisa em 2009. Michele foi a primeira professora entrevistada. A nossa interação em gravação de áudio aconteceu no dia 28 de dezembro de 2017 e durou 53'33".

\section{5) Fundamentação da Teoria Linguístico-Discursiva}

É no entrelace da Sociolinguística Interacional, da Linguística Aplicada e da proposta laboviana (1972) e as novas concepções sobre narrativas (LINDE, 1993; BAMBERG \& GEORGAKOPOULOU, 2008; BASTOS \& BIAR, 2015, MOITA LOPES, 2001; 2006; 2013) que esta fundamentação linguístico-discursiva é conduzida.

\section{1) A estadia da Linguística Aplicada}

Os dados deste estudo corroboram os motivos pelos quais optei pela Linguística Aplicada (LA) para dar suporte às minhas reflexões. Neles, há questionamentos sobre como os professores constroem suas identidades sociais em suas histórias de vida e experiências na escola pública em que trabalham e como conflitos urbanos (tiroteios, operações, barricadas, entre outros) que ocorrem em torno de uma escola pública afetam a prática docente. Vale ressaltar que este estudo compreende "a necessidade de pensar o mundo por um olhar não-ocidentalista" (MOITA LOPES, 2013, p.87), pois o olhar ocidentalista entende que o conhecimento não tem nada a ver com o modo como as pessoas vivem suas vidas cotidianas, seus sofrimentos, seus projetos políticos e desejos. Sendo assim, acredito que não é possível produzir conhecimento de uma forma imune às questões que estou levantando E, seguindo os passos da LA transgressiva e indisciplinar, 
de Moita Lopes (2006), entendo que a divisão que afasta a teoria da prática não se sustenta.

Portanto, no presente estudo, sete professores que trabalham em uma escola da rede pública estadual do Rio de Janeiro, localizada em um bairro periférico de São Gonçalo onde estão ocorrendo conflitos urbanos, se reconstroem e coconstroem ao falar sobre questões que atravessam as suas práticas como docentes. Uma das professoras sou eu, que também assumo o papel de pesquisadora, construo o conhecimento junto aos outros professores/colegas de trabalho, desafiando assim a tradição ocidentalista de pesquisa ou o chamado "conhecimento científico tradicional e sua ignorância em relação às práticas sociais vividas pelas pessoas de carne e osso no dia-a-dia" (MOITA LOPES, 2006, p.88).

\section{2) A Sociolinguística Interacional e a análise de narrativas}

A pesquisa se alinha à abordagem sociointeracional do discurso, que adota uma perspectiva interdisciplinar por fazer considerações a Linguística, a Sociologia, a Antropologia, a Filosofia, a Psicologia Social, o que envolve relações entre linguagem, cultura e sociedade. Segundo Schiffrin (1994), os estudos precursores dessa abordagem e que influenciaram trabalhos atuais foram do sociólogo de Erving Goffman e do antropólogo e linguista John Gumperz. Assim, os estudos desenvolvidos por tais autores preconizam uma visão de discurso relacionando o uso da linguagem como forma de prática social.

Conceitos como footing e as pistas de contextualização estão presentes na análise de dados com o apoio da abordagem teórica tratada nesta pesquisa e de acordo com Goffman e Gumperz. A noção de footing, conforme Goffman (1979), são os alinhamentos, que são introduzidos, negociados, ratificados (ou não), co-sustentados e modificados na interação. Eles exprimem o modo como gerenciamos a produção ou a recepção das elocuções em um encontro social, ou seja, na interação face a face (RIBEIRO \& GARCEZ, 1998). Gumperz (1982) destaca as pistas de contextualização que contribuem para a sinalização de pressupostos contextuais que são: (i) as pistas paralinguísticas, ou seja, ritmo (tempo da fala), pausas, hesitações e risos (ii) as pistas prosódicas representadas por entonação, acento e tom e, (iii) as pistas linguísticas, como a alternância de código, de dialeto ou de estilo, escolhas lexicais e sintáticas, expressões formulaicas e aberturas e fechamentos conversacionais (RIBEIRO \& GARCEZ, 1998). 


\section{3) Narrativas de acordo com Labov e autores posteriores}

Este estudo é fundamentado em uma visão sociolinguística interacional de narrativa. Esclarecendo esta perspectiva baseada em análise de narrativas, segundo Bastos \& Biar (2015), as narrativas podem ser definidas como o discurso construído na ação de se contar histórias em contextos cotidianos ou institucionais, em situações ditas espontâneas ou em situação de entrevista como pesquisa social, que é o caso desta pesquisa.

Segundo Labov (1972), a narrativa organiza-se por meio de seis componentes estruturais: sumário ou resumo (resumo inicial do que virá a seguir), orientação (contextualização da história, ou seja, identificação de personagens, tempo, lugar e atividades narradas), ação complicadora (quando efetivamente o narrador deixa de contextualizar e passa a contar o que aconteceu, sendo a parte da narrativa que responde a pergunta “e o que aconteceu depois?”), avaliação (parte da narrativa que demonstra a relevância da história e a explicitação da postura do narrador em relação à narrativa), resultado (desfecho das ações narrativas) e coda (encerramento da narrativa que avalia os efeitos da história).

Vale ressaltar que, embora Labov (1972) tenha desenvolvido um trabalho pioneiro sobre análise de narrativas, estudos posteriores somaram-se ao que Labov havia pesquisado até então como os estudos de Linde (1993), Riessman (1993), Bamberg \& Georgakopoulou (2008), Bastos \& Biar (2015), Biar (2012) e Moita Lopes (2001). Os estudos de Linde (1993), alinhando-se a uma visão socioconstrucionista, redimensionam os estudos da narrativa dentro de uma perspectiva que se apoia no conceito de histórias de vida como unidade oral da interação social.

Linde (1993, p.152) traz também em seus estudos a noção de avaliação como "um fator essencial para a compreensão de uma determinada pessoa, de suas ações e de seu contexto". A autora analisa a estreita relação entre avaliação e prática social, ao analisar a avaliação como elemento de negociação em interações sociais. Tal relação alinha-se a este estudo que pretende estabelecer uma conexão entre avaliação (posicionamento) e (re) construção identitária.

Os estudos de Bamberg \& Georgakopoulou (2008) também apresentam contribuições consideravelmente relevantes no que diz respeito à análise de narrativas trazendo a proposta de narrativas não-canônicas. Os autores propõem uma análise 
direcionada para o que eles identificam como pequenas histórias ou micronarrativas que vão além das categorias propostas por Labov, pois o "termo micronarrativas abrange uma gama de atividades narrativas subrepresentadas, como histórias sobre eventos em andamento, eventos futuros ou hipotéticos e eventos compartilhados" (BAMBERG \& GEORGAKOPOULOU, 2008, p. 381).

\section{4) Posicionamentos dos professores diante dos desafios e um olhar voltado para eles nesta pesquisa}

Do mesmo modo que Bamberg (1997), neste trabalho eu também considero a agência uma mola impulsionadora das ações dos indivíduos no sentido "sujeito para o mundo", que é, portanto, uma questão central nas práticas de posicionamento. É necessário compreender que usar a linguagem é uma ação social. Assim, os sujeitos se alicerçam em função da agência e dos papéis sociais de liderança que possam vir ou não a assumir.

Os estudos de Bamberg (1997; 2002) e Bamberg \& Georgakopoulou (2008) abarcam de forma relevante a noção de agentividade e de posicionamento que tratam, ambas, de uma agência no processo de construção de self/si. Durante a interação, os agentes sociais se constroem como: (i) aqueles que estão no controle ou (ii) aqueles que estão à mercê de forças externas, ou que é recompensado por Deus, pela sorte, pelo destino ou por qualidades pessoais, por exemplo, coragem, nobreza ou caráter (BAMBERG, 2002). Com isso, compreende-se como os falantes constroem seus selves e se posicionam diante de discursos culturais (hegemônicos).

De acordo com Bamberg (1997; 2002), o posicionamento narrativo é orientado por três níveis de análise: o primeiro nível se refere à história, o segundo à interação e o terceiro nível à pergunta “Quem sou eu?”. Os três níveis foram desenvolvidos pelo autor, de maneira que, a análise é iniciada em nível localmente situado (nível 1), isto é, em nível textual, e segue em nível interacional (nível 2) chegando até o nível do macro contexto social (nível 3). As análises dos posicionamentos nestes três níveis corroboram com a projeção dos participantes da pesquisa como agentes sociais (BAMBERG, 1997; 2002). Vejamos detalhadamente:

O nível 1: nesse ponto, o analista deverá observar as escolhas linguísticas do narrador a fim de perceber a localização dos "personagens" (entendidos nesta pesquisa como sujeitos) no mundo da história e sua construção como vítimas, algozes, agentes etc. 
Trata-se, em linhas gerais, de se compreender o assunto de uma história;

$O$ nível 2: Aqui o interesse da análise se volta para o momento da interação, pois é quando nos "perguntamos por que uma história é contada em um dado ponto da interação" e qual efeito narrador "está tentando alcançar com a história" (BAMBERG, 2002, p.157). A audiência numa narrativa adquire o status de participante.

$O$ nível 3: Trata-se do momento em que o analista deve deslocar seu foco de observação para os discursos socialmente disponíveis. Como os narradores se posicionam para si próprios? Trata-se de uma tentativa por parte do narrador de definir o seu self para si e para os outros.

De acordo com Bamberg (2002, p.156), o nível 3 de posicionamento está associado às posições tomadas diante de 'Discursos com ' $\mathrm{D}$ ' maiúsculo, ou seja, formas sociais de comunicação preexistentes”. No terceiro nível, há um cuidado em compreender como a linguagem é usada para defender os pontos de vista do narrador, suas crenças, que vão além daquela conversa e o posicionam em um contexto macro. Portanto, o nível 3 foca no posicionamento do sujeito face aos Discursos que circulam na sociedade e ideologias.

\section{6) Um recorte da análise}

A pesquisa está fundamentada em uma visão de discurso que favorece a coconstrução de significados, sendo as entrevistas compreendidas como eventos sociais e as narrativas como um modo de dispor e dar sentido à vida social. Cada história de vida (LINDE, 1993) é compreendida como uma grande narrativa composta por diversas narrativas, micronarrativas, relatos, sendo todos interligados. Os dados apresentados são da professora já descrita neste artigo, que aceitou fazer parte deste estudo e com quem fiz a primeira entrevista: Michele.

\section{1) Conhecendo a realidade através de suas histórias de vida e narrativas de trajetórias profissionais}

No excerto a seguir, Michele e eu apresentamos um alinhamento que constrói o nosso posicionamento como alunas, assim como os nossos alunos, pois já fomos estigmatizadas/discriminadas assim como eles pela questão financeira e também por ter pertencido a uma estrutura familiar fora dos moldes da sociedade, como cita Michele 
(linhas 4-8; 10). Tal perspectiva ecoa o ponto levantado por Goffman (1963, p.149) que, ao teorizar normalidade e estigma, os coloca como "perspectivas geradas em situações sociais". Assim como Michele, alguns alunos e eu, outros em tantas partes do país enfrentam essa mesma realidade.

Michele: Excerto 1- “Eu fui uma dessas crianças que estudam aqui” (39'51” - 41'56”)

\begin{tabular}{|c|c|c|}
\hline 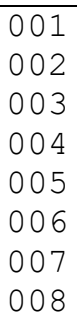 & Michele & $\begin{array}{l}\text { eu fui uma... uma dessas crianças que estudam aqui. eu } \\
\text {... eu não fui aluna do colégio distrito ((nome } \\
\text { fictício)), eu fui aluna do irene, que é outro colégio } \\
\text { daqui do bairro. toda vez que eu olho para esses alunos, } \\
\text { eu lembro de mim, sabe? que eu fui uma criança pobre, } \\
\text { tão pobre quanto eles ou MAIS. eu fui uma criança } \\
\text { discriminada também porque aqui na minha época era } \\
\text { muito ruim você não ter pai. }\end{array}$ \\
\hline 009 & Viviane & Uhum \\
\hline $\begin{array}{l}010 \\
011 \\
012 \\
013 \\
014 \\
015 \\
016 \\
017 \\
018 \\
019 \\
020 \\
021 \\
022\end{array}$ & Michele & $\begin{array}{l}\text { meu pai largou a minha mãe com dois filhos pequenos. } \\
\text { minha mãe trabalhava o dia inteiro. então, a gente } \\
\text { sofreu muito preconceito. eu vejo essas crianças } \\
\text { pobrezinhas que não tem dinheiro para nada. é... a } \\
\text { gente não comprava roupa.... a gente ganhava roupa } \\
\text { usada dos outros. e eu vejo meus alunos... eu me vejo } \\
\text { nessas crianças, sabe? por isso que eu tenho tanto essa } \\
\text { coisa sabe? por isso que eu tenho tanto essa coisa do } \\
\text {... do bairro. e assim... com todas essas coisas, e com } \\
\text { todos os problemas, tem muita coisa boa que a gente } \\
\text { pode tirar daqui. essas crianças precisam de uma } \\
\text { oportunidade. a gente vÊ, as vezes uma criança que tem } \\
\text { tudo para ser uma coisa ruim. }\end{array}$ \\
\hline 023 & Viviane & verdade. \\
\hline $\begin{array}{l}024 \\
025 \\
026 \\
027 \\
028\end{array}$ & Michele & $\begin{array}{l}\text { [e é] uma criança boa. e assim, por isso que eu tento } \\
\text { dar o meu melhor. eu nunca cheguei aqui na escola e } \\
\text { pensei..."ah.. eu vou dar isso e tá bom". para quem- } \\
\text { não quer. SEMPRE tem... aquela... até naquelas piores } \\
\text { turmas tem [aqueles] }\end{array}$ \\
\hline 029 & Viviane & [uhum] \\
\hline $\begin{array}{l}030 \\
031 \\
032\end{array}$ & Michele & $\begin{array}{l}\text { [dois] ou três que ali que você... que } \\
\text { você olha para ele, e você vê que... quando você está } \\
\text { explicando a matéria você deve sentir isso }\end{array}$ \\
\hline 033 & Viviane & sim, sim. \\
\hline $\begin{array}{l}034 \\
035\end{array}$ & Michele & $\begin{array}{l}\text { e olha que tem alguém prestando atenção em você. nem } \\
\text { que seja um, você fala " caraca, [ganhei]". }\end{array}$ \\
\hline 036 & Viviane & 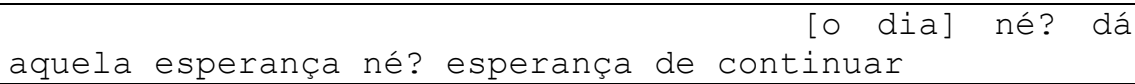 \\
\hline $\begin{array}{l}038 \\
039\end{array}$ & Michele & $\begin{array}{l}\text { [aque: lezinho] ali tá te olhando, tá prestando atenção } \\
\text { no que você tá falando. " pô, ganhei né?" }\end{array}$ \\
\hline $\begin{array}{l}040 \\
041 \\
042 \\
043 \\
044\end{array}$ & Viviane & $\begin{array}{l}\text { é isso que eu também penso. eu também tive uma infância } \\
\text { difícil, complicada. eu acho que isso faz com que a } \\
\text { gente ainda tenha motivação, né. esperança de continuar } \\
\text { trabalhando com eles, porque a gente também precisa } \\
\text { disso. }\end{array}$ \\
\hline $\begin{array}{l}045 \\
046\end{array}$ & Michele & $\begin{array}{l}\text { a gente precisou de professores que olhassem [para } \\
\text { gente }\end{array}$ \\
\hline 047 & Viviane & [para gente]...sim= \\
\hline
\end{tabular}




\begin{tabular}{|l|l|l|l|}
\hline 048 & Michele & =e que nos vissem, além de tudo, além \\
049 & & de todo o problema. a escola onde eu estudava também \\
050 & & era complicada, muitas vezes a gente precisou de \\
051 & & professores que olhassem para gente. tivessem aquela \\
052 & & atenção, que vissem além de tudo. \\
\hline
\end{tabular}

Inicio a análise pelo nível 1 de acordo com Bamberg (1997; 2002), ou seja, etapa em que o foco é a construção dos sujeitos da história com relação uns aos outros. Há duas histórias simultâneas acontecendo no excerto. A primeira é sobre alunos de escola pública que são discriminados/estigmatizados (GOFFMAN, 1963) por isso, pela sociedade e por estudarem em um local que também é estigmatizado por serem, em sua maioria, de uma classe não privilegiada e que vem sofrendo problemas com o tráfico de drogas no entorno e com a falta de políticas públicas (TAVARES,2003). Já a segunda história se encaixa com a primeira e trata do estigma que as professoras também sofreram enquanto alunas. A fala reportada de Michele na linha 26 indica que alguns alunos também são estigmatizados por outros professores pelos seus descréditos não só no ensino público como na possibilidade de ser feito um trabalho com esses alunos diante da situação de violência no entorno. Enquanto nas linhas 48 a 52, Michele nos mostra que essa é uma questão já vivenciada por ela como aluna, porém encontrou professores que não a estigmatizaram e acreditaram em seu potencial (FREIRE,1981; MOITA LOPES,2003), e, assim, nos alinhamos quando confirmo e compartilho da mesma experiência como exaluna (linha 47).

Os primeiros minutos (linha 1-2), ou seja, o sumário e em seguida a orientação na narrativa de Michele, já nos esclarece qual é o seu posicionamento diante da sua situação como professora. Como já foi estigmatizada, ela não deseja o mesmo para os seus alunos e, como professora, os entende. O nível 2 de posicionamento se entrelaça ao nível 1 quando ocorre a interação entre mim e Michele, pois sou a sua audiência e ela tem consciência disso, surgindo pistas linguísticas/de contextualização (GUMPERZ, 1982) que neste caso são as escolhas lexicais como o uso do pronome "você" (linhas 34-35) para relatar a própria experiência e o "a gente" (linha 45) como recursos de persuasão e também do meu envolvimento com a história que contribuem para o nosso alinhamento no segundo nível de posicionamento e transformam o enquadre de relação profissional em um enquadre pessoal (GOFFMAN, 1974).

Além disso, duas ações complicadoras vão se entrelaçando na narrativa de Michele quando ela diz "meu pai largou a minha mãe com dois filhos pequenos. minha mãe trabalhava o dia inteiro. então, a gente sofreu muito 
preconceito" (linhas 10-12) ao falar da sua própria história de vida (LINDE, 1993) e quando se refere a sua experiência profissional com seus próprios alunos "eu vejo essas crianças pobrezinhas que não tem dinheiro para nada."(linhas 12-13). Elas são seguidas pelas avaliações "com todas essas coisas, e com todos os problemas, tem muita coisa boa que a gente pode tirar daqui" (linhas 18-20), "essas crianças precisam de uma oportunidade" (linhas 20-21) e "a gente Vê, as vezes uma criança que tem tudo para ser uma coisa ruim" (linhas 21-22). Com essas ações complicadores e avaliações, Michele se mostra uma professora preocupada com o destino dos seus alunos e, até mesmo receosa que alguns comecem a fazer parte do tráfico de drogas, embora ela não perca as esperanças ao avaliar que, o que eles precisam é de uma oportunidade, assim como ela teve. Aqui, Michele e eu coconstruímos a coda (linha 40) quando digo à ela que "é isso que eu também penso" e estamos tratando de questões que atravessam as nossas práticas como docentes (MOITA LOPES, 2006). Como pode ser visto, a história de vida está interligada à prática profissional. As pessoas estão sempre construindo a história de si e da escolha da profissão simultaneamente. Consequentemente, o que vemos aqui é uma simbiose entre local de moradia e profissão.

Observando as outras duas camadas de análise, percebo o quanto Michele e eu reconstruímos e coconstruímos nossos selves ao lembrar de profissionais que foram bons exemplos em nossas vidas e nos quais tentamos nos espelhar em nossa prática docente. Lembramo-nos de que essas pessoas voltaram seus olhares e atenção para nós duas independentemente dos problemas dessa época (linhas 45-52). Tal perspectiva corrobora a importância do olhar sobre o mundo social na análise das narrativas (MOITA LOPES, 2006). Além disso, o discurso hegemônico de discriminação do pobre pela sua condição social está presente em nossa sociedade, ou seja, no macro contexto social, conforme foi colocado na interação (BAMBERG,1997; 2002).

\section{2) Os desafios devido à violência causada pelos conflitos urbanos no entorno da escola e suas consequências}

Não há como não relacionar essas questões aos processos de educabilidade dos jovens, pois são justamente eles quem mais sofrem as repercussões da escalada da violência urbana em suas ruas e bairros, por se tornarem alvos fáceis das "balas perdidas", tanto dos traficantes, quanto da própria polícia, pouco preparada para intervenção nessas áreas de conflitos (TAVARES, 2010). 
Um outro desafio é o caráter empresarial do tráfico de drogas, que utiliza mão de obra jovem e de áreas periféricas, seduzindo jovens pelos ganhos superiores aos de empregos formais, ocasionando prisões ou mortes prematuras, além do aumento da violência (BIAR, 2012). Além disso, há fluxos socioeconômicos poderosos que redesenham os espaços urbanos, redefinem as dinâmicas locais, redistribuem bloqueios e possibilidades (TELLES, 2007). Consequentemente, observa-se uma ausência de políticas públicas para as periferias, o que acaba construindo novas relações (espaço/tempo) além da sensação de que a população dessas áreas vivencia uma situação de sobrevivência urbana, conforme é relatado no excerto 2.

- Michele

Excerto 2- "Isso reflete dentro da escola de uma forma muito grande” (14'54"- 16'17”)

\begin{tabular}{|c|c|c|}
\hline $\begin{array}{l}001 \\
002\end{array}$ & Viviane & $\begin{array}{l}\text { eu me lembro que quando eu cheguei em 2014, não tinham } \\
\text { essas barricadas aqui perto. }\end{array}$ \\
\hline 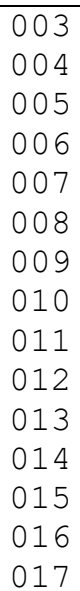 & Michele & $\begin{array}{l}\text { isso... tráfico de drogas aqui nessa região sempre } \\
\text { houve, mas era lá em baixo, eles não subiam ...né. } \\
\text { não tinha essa violência TODA que a gente tem hoje. } \\
\text { então eu acho que essa violência... essa-... a escola } \\
\text { fica no MEIo... sabe? de tudo, de uma área muito } \\
\text { violenta, uma área onde o tráfico de drogas é muito } \\
\text { INTENSo. então eu acho que isso reflete de:ntro da } \\
\text { escola de uma forma muito grande. eu acho que } \\
\text { determina muito das vezes até o funcionamento da } \\
\text { escola. a gente sabe que quando tem operação a escola } \\
\text { fica vazia, mesmo que a escola esteja aberta. a gente } \\
\text { sabe que quando tem operação policial no BAIRRO, os } \\
\text { alunos mudam o comportamento quando estão na escola, } \\
\text { então ficam mais AGITA:Dos, ficam mais PREOCUPA:Dos, } \\
\text { mais <tensos>. }\end{array}$ \\
\hline 018 & Viviane & Verdade \\
\hline 019 & Michele & e isso também reFLEte no aprendizado do aluno \\
\hline 020 & Viviane & Uhum \\
\hline $\begin{array}{l}021 \\
022 \\
023 \\
024 \\
025 \\
026 \\
027 \\
028 \\
029\end{array}$ & Michele & $\begin{array}{l}\text { e também na questão da violência mesmo deles se } \\
\text { tornarem mais violentos, porque muitos alunos tem o } \\
\text { entorno como única referência de lugar. a única } \\
\text { referência de lugar é isso aqui. então eles veem o } \\
\text { irmão, o vizinho entrando para o tráfico, de repente } \\
\text { desfilando com uma arma <na mão>, colocando o medo... } \\
\text { muitas das vezes essas pessoas são os espelhos para } \\
\text { os nossos próprios alunos. infelizmente eles trazem } \\
\text { essa violência para dentro da escola. }\end{array}$ \\
\hline
\end{tabular}

Ao longo da interação entre mim e Michele, o alinhamento faz parte de nossa fala. Michele inicia a micronarrativa se posicionando no nível 1 (BAMBERG, 2002) como moradora alternando o seu posicionamento como professora da escola a partir da linha 9, fazendo do resumo (linhas 3-4) uma estratégia que coopera com o que eu havia dito nas linhas 1-2 e esclarece a história que se inicia. Posteriormente, a narrativa de Michele 
apresenta a ação complicadora (linha 5) e conduz uma sequência de avaliações das linhas 6 a 17 em que ela se posiciona (nível 2) sobre a violência no entorno da escola e sobre o quanto isso afeta a nossa prática docente e a rotina escolar.

Michele se utiliza de recursos linguísticos como a entonação e escolhas lexicais (GUMPERZ, 1982) "MEIO" (linha 7), "InTEnso" (linha 9) e "de:ntro da escola de uma forma muito grande" (linhas 9-10), que consigam dar conta de sua mensagem, ou seja, mostrar o quanto os conflitos urbanos impactam e modificam vidas até mesmo dentro do ambiente escolar. Além disso, há uma pista linguística (GUMPERZ, 1982) isto é, a escolha lexical de "a gente" com a repetição da palavra, o que significa que Michele utiliza-se desse recurso para me incluir, promovendo o nosso alinhamento através do compartilhamento de experiências e isso corrobora com o entendimento sobre identidades como uma coconstrução social nos encontros interacionais (MOITA LOPES, 2003).

Uma marca presente na narrativa de Michele é como ela constrói o seu self com expressiva agentividade (BAMBERG \& GEORGAKOPOULOU, 2008) como moradora e professora. Michele continua uma nova sequência de avaliações (linhas 21-26) e, de acordo com a sua narrativa, o resultado é que "muitas das vezes essas pessoas são os espelhos para os nossos próprios alunos" (linhas 27-28). Como podemos ver, não há como não relacionar essas questões aos processos de educabilidade dos jovens (TAVARES, 2010).

Compreende-se através do posicionamento (nível 3) que há uma associação entre violência do ambiente e por parte dos alunos nas avaliações da narrativa de Michele que situações recorrentes de conflito urbano estão se tornando banais, "quase-normais, uma muito peculiar normalidade construída num equilíbrio muito frágil, no fio da navalha" (TELLES, 2007, p.209), conforme Michele encerra a sua narrativa através da coda avaliativa "infelizmente eles trazem essa violência para dentro da escola" (linhas 28-29). Portanto, essa é uma questão que não pode ser vista como normal por falta de políticas públicas, de gestão do social e administração de suas urgências (TELLES, 2007) que possam, de fato, garantir o direito à educação e a ascensão social dos que vivem em áreas periféricas evitando a exclusão social.

\section{3) Estigma social e resistências}

Através da narrativa de Michele no excerto 1, é compreendido que há um discurso hegemônico de discriminação/estigmatização do pobre pela sua condição social presente 
em nossa sociedade, ou seja, no macro contexto social, conforme foi colocado na interação (GOFFMAN, 1963). A narrativa de Michele dialoga com dois momentos de posicionamento: o primeiro como moradora e ex-aluna de escola pública e o segundo como professora da escola onde trabalhamos.

Há duas histórias simultâneas acontecendo no excerto. A segunda é sobre alunos de escola pública que são discriminados/estigmatizados (GOFFMAN, 1963) pela sociedade e também por estudarem em um local que também é estigmatizado por serem, em sua maioria, de uma classe não privilegiada e que vem sofrendo problemas com o tráfico de drogas no entorno e com a falta de políticas públicas (TAVARES, 2003). Já a primeira história se encaixa com a segunda por meio de ações complicadoras que vão se entrelaçando na narrativa de Michele quando ela diz "meu pai largou a minha mãe com dois filhos pequenos. minha mãe trabalhava o dia inteiro. então, a gente sofreu muito preconceito". Ao falar da sua própria história de vida (LINDE, 1993), capta-se a clareza de que o estigma social sofrido por Michele aconteceu pelos mesmos motivos que hoje ela vê em nossos alunos.

Levando em consideração questões de classe social, segundo Bauman (2013) um dos maiores problemas da atualidade é a questão da desigualdade social, que no cenário em que vivemos está virando uma marca registrada na história. No entanto, o que parece ocorrer é que a desigualdade social ultrapassa as questões puramente econômicas. $\mathrm{O}$ fator responsável é uma enorme de desigualdade distributiva e, que se amplia a uma atração fatal entre pobreza e vulnerabilidade social, que é a realidade de muitos de nossos alunos estigmatizados por essas questões conforme nas linhas 12-13.

Somos diariamente bombardeados pelas mídias que são as principais difusoras de ideologias hegemônicas que focam em marcas de descrédito que geram sensação de incapacidade e estigmatização para quem vive na vulnerabilidade social de uma área periférica. Michele mostra em sua narrativa qual é o seu posicionamento com relação aos nossos alunos (linhas 18-22), sendo o seu posicionamento discursivo um ato de resistência às ideologias opressoras presentes nos discursos circulantes.

\section{7) Considerações Finais}

As histórias de vida dos professores estão interligadas à prática profissional e isso ocorre simultaneamente. Nessas histórias, como vimos nos excertos de Michele, são narrados acontecimentos de sua infância, adolescência e fase adulta, gerando 
retrospectiva ao contar a história de si e da escolha da profissão. Consequentemente, há uma simbiose entre o local de moradia e a profissão, pois a vontade de ser professor manifesta-se como um ato de resistência desses profissionais contra Discursos estigmatizantes que julgam os moradores de áreas periféricas como incapazes de ter uma formação de nível superior.

A violência é apontada como algo que está determinando o funcionamento da dinâmica escolar, consequentemente afetando a prática docente de forma negativa. Além disso, a violência é enquadrada como uma mudança numa relação antes/depois. Antes a preocupação era somente com as questões sociais referentes a pobreza e a falta de infraestrutura. Depois se transformou em um somatório de pobreza, falta de infraestrutura e violência. Os nossos posicionamentos e alinhamentos indicam que apesar dos conflitos urbanos vivenciados que afetam a dinâmica escolar, os professores não pensam em fazer dessa situação um pretexto para não exercerem uma prática de qualidade para o público da comunidade local pelo fato deles se verem e se construírem nela, não pensando em deixá-la. Os posicionamentos (nível 3) apontam que os professores, como vimos nos excertos de Michele, se constroem como agentes sociais reflexivos sobre os Discursos hegemônicos e que não pretendem aceitá-los, pois em suas falas subvertem as relações de poder que tentam representar negativamente o trabalho do professor.

\section{Referências}

BAMBERG, Michael. Positioning Between Structure and Performance. In: Journal of Narrative and Life Story, v. 7, n. 1-4, pp. 335-342, 1997.

Construindo a masculinidade na adolescência: posicionamentos e o processo de construção da identidade aos 15 anos. In: MOITA LOPES, L.P. \& BASTOS, L. C. (Orgs.) Identidades: recortes multi e interdisciplinares. Campinas: Mercado de Letras, 2002.

; GEORGAKOPOULOU, Alexandra. Small stories as a new perspective in narrative and identity analysis. Text \& Talk, [S.1.], v. 28, n. 3, pp. 377-396, 2008.

BASTOS, L.C.; BIAR, L.A. Análise de narrativa e práticas de entendimento da vida social. D.E.L.T.A. Documentação de Estudos em Linguística Teórica e Aplicada, v. 31, n. especial, p. 97-125, fevereiro de 2015.

BAUMAN, Zygmunt. Sobre educação e juventude: conversas com Ricardo Mazzeo. Rio de Janeiro: Zahar, 2013.

BIAR, Liana de Andrade. "Realmente as autoridades veio a me transformar nisso": narrativas de adesão ao tráfico e a construção discursiva do desvio. Tese (Doutorado em Estudos da Linguagem). Pontifícia Universidade Católica, Rio de Janeiro, 2012. 
DENZIN, Norman; LINCOLN, Yvonna. A disciplina e a prática da pesquisa qualitativa. In: DENZIN, Norman; LINCOLN, Yvonna. O planejamento da pesquisa qualitativa: teorias e abordagens. Porto Alegre: Artmed, 2006.

DOMINGUEZ, Marcos Thimoteo. Jardim Catarina: memória e movimentos cotidianos numa periferia Fluminense. Anais do XI Encontro Nacional de História Oral: memória, democracia e justiça. Rio de Janeiro, 2012.

FANFANI, Emilio Tenti. La condición docente: análises comparado de la Argentina, Brasil, Peru y Uruguay. Buenos Aires: Siglo XXI, Editores Argentina, 2007.

FERREIRA, Rodolfo. O professor invisível: trabalho docente e vocação. Quartet: Rio de Janeiro, 2003.

FREIRE, Paulo. Pedagogia do oprimido. Rio de Janeiro: Paz e Terra, 1981.

GOFFMAN, Erving. Stigma: notes of the management of spoiled identity. New York: Anchor Books Edition, 1963.

Frame Analysis. New York: Harper \& Row, 1974.

Footing. In: RIBEIRO, B. T. e GARCEZ, P. M. (Orgs.). Sociolinguística interacional. São Paulo: Edições Loyola, [1979] 2013.

GUMPERZ, John. Convenções de contextualização. In: RIBEIRO, B. T.; GARCEZ, P. (Orgs). Sociolinguística Interacional. São Paulo, Edições Loyola, [1982] 2002.

LABOV, William. The transformation of experience in narrative syntax. In: LABOV. W. Language in the inner city. Philadelphia: University of Philadelphia Press, 1972.

LINDE, Charlotte. Life stories: the creation of coherence. New York: Oxford University Press, 1993.

MENDES, Pitter. E assim surge.... Jardim Catarina. São Gonçalo: Ponto de Cultura, 2012.

MÉNDEZ, Mariza. Autoethnography as a research method: advantages, limitations and criticisms. Colombian Applied Linguistics Vol. 15, n.2, 2013.

MINAYO, Maria Cecília de Souza. O desafio do conhecimento pesquisa qualitativa em saúde. 2a ed. São Paulo: Hucitec/ Abrasco, 1993.

MISHLER, Elliot. Research Interviewing: Context and Narrative. Cambridge: Havard University Press, 1986.

MOITA LOPES, Luiz. Paulo. Práticas narrativas como espaço de construção das identidades sociais: uma abordagem socioconstrucionista. In: RIBEIRO, B.T; LIMA, C. C; DANTAS, M. T. L. Narrativa, Identidade e Clínica. Rio de Janeiro: Edições IPUB, 2001. 
Linguística aplicada e vida contemporânea: problematização dos construtos que têm orientado a pesquisa. In: Moita Lopes, L. P. (Org.). Por uma linguística aplicada indisciplinar. São Paulo: Parábola Editora, 2006.

Agenda de pesquisa e ação em linguística aplicada: problematizações. In: MOITA LOPES, L. P. Linguística aplicada na modernidade recente. Fertschrift para Antonieta Celani. São Paulo. Parábola Editora, 2013.

PINHO, Osmundo. Araújo. A vida em que vivemos: raça, gênero e modernidade em São Gonçalo. Estudos Feministas, Florianópolis, 14 (1): p. 169 -198, janeiro/abril de 2006.

PORTES, Ecio Antonio. Trajetórias escolares e vida acadêmica do estudante pobre da UFMG: um estudo a partir de cinco casos. Tese (Doutorado em Educação), Universidade Federal de Minas Gerais, Belo Horizonte, 2001.

RIBEIRO, Bruno Teixeira, GARCEZ, Pedro de Moraes. (Orgs). Sociolinguística Interacional. 2 ed. São Paulo: Edições Loyola, 1998.

RIESSMAN, Catherine Kohler. Narrative analysis. Qualitative Research Methods Series, n.30. Newbury Park, CA: Sage, 1993.

SACKS, Harvey, SCHEGLOFF, Emanuel, JEFFERSON, Gail. A simplest systematics for the organization of turn-taking for conversation", Language, vol. 50, no. 4, 1974.

SANTOS, Boaventura de Souza. A Universidade no século XXI. São Paulo: Cortez Editora, 2004.

SCHIFFRIN, Deborah. Approaches to Discourse. Blackwell Textbooks in Linguistics, Oxford: Blackwell, 1994.

TAVARES, Maria Tereza Goudard. Os Pequenos e a Cidade: o papel da escola na construção de uma alfabetização cidadã. Tese de Doutorado em Educação, Universidade Federal do Rio de Janeiro, Rio de Janeiro, 2003.

A (s) infância (s) e a cidade: discutindo processos formativos de crianças nos territórios gonçalenses. Projeto de Iniciação Científica, UERJ, Rio de Janeiro, 2010.

TELLES, Vera da Silva. Transitando na linha de sombra, tecendo as tramas da cidade, In: OLIVEIRA, Francisco, RIZEK, Cibele Saliba (Orgs). A era da indeterminação. São Paulo: Boitempo, 2007.

\title{
TEACHING AND URBAN CONFLICTS: \\ NARRATIVES AND DISCURSIVE POSITIONINGS OF TEACHERS IN CONTEXTS MARKED BY VIOLENCE
}

\begin{abstract}
The present study looks at a state school located in Rio de Janeiro which has undergone changes as a result of urban conflicts during recent years. By studying narrative
\end{abstract}


constructions and discursive positioning (BAMBERG, 1997; 2002), this paper aims to investigate how teachers construct their identities, how they deal with the challenges of violence and how they position themselves in relation to Discourses on education and violence.

\section{Keywords}

Public School. Teachers' Identity. Narratives. Life Stories. Positionings 